\title{
Integrating health care for mothers and children in refugee camps and at district level
}

\author{
Assad Hafeez, Rubina Riaz, Samin Ullah Shah, Javed Pervaiz, David Southall
}

Health care for mothers and children is inadequate in most refugee situations and in poorly resourced countries. The authors argue that, as well as providing primary (home based) care for basic health care, there is a need to integrate primary care with adequately functioning hospital based care for a healthcare system to succeed

\begin{abstract}
Child Advocacy International Pakistan, 97 Blue Area, Gondal Plaza, Islamabad, Pakistan Assad Hafeez honorary secretary general

Rubina Riaz obstetrician and gynaecologist Samin Ullah Shah paediatrician

Provincial

Department of Health,

Commissionerate for Afghan Refugees, Peshawar, Pakistan

Javed Pervaiz head of medical services

In poorly resourced countries, a failure to link primary (home based) care effectively to that available in the local government run general hospitals is common. Communication between home based care and hospital based care is rare. The extremely poor services available in many district hospitals ${ }^{1}$ deter families from taking their relatives there for treatment. The patients, supported by their families, would rather die at home than in an ineffective, poorly resourced, and often grossly unhygienic and unwelcoming hospital. There are often no effective links between the primary and hospital care facilities. If the sickest patients detected by primary health workers have nowhere to go, the system fails those most in need. Equally, both home based and hospital based care need to be individually functioning adequately as well as being integrated, and a poverty of services in either sector results in a failing healthcare system.
\end{abstract}

Child Advocacy International, Newcastle under Lyme ST5 1ND

David Southall honorary medical director

Correspondence to: D Southall davids@ doctors.org.uk

BMJ 2004;328:834-6

A similar situation exists in camps for refugees, where the prime objective of humanitarian aid during emergencies (often of long standing when caused by armed conflict) is to prevent mortality through the delivery of primary health care and other basic services such as shelter, nutrition, water, sanitation, and protection. The public health doctors who largely control and direct the funds for primary health care, for sound reasons, regard this as the most cost effective approach. However, this form of aid does not address aspects of mortality and morbidity due to acute and serious medical, obstetric, and surgical problems or to chronic diseases that need specialist input. An absence of effective hospital care in or near refugee placements means that most of the sickest patients do not receive adequate treatment, undermining the effectiveness of the primary health care provided.

From experience of emergency work in Afghanistan, Bosnia, and Kosovo and of healthcare delivery in Pakistan and sub-Saharan Africa, Child Advocacy International realised that both home based and hospital care need to be functioning adequately as well as being integrated and that a poverty of services in either sector resulted in a failing healthcare system. These experiences also emphasised the importance of maternal and child health services working closely together.

\section{Case study 1: Three Afghan refugee camps in Pakistan}

Most of the five million refugees from Afghanistan live in Pakistan and Iran in camps or in squalid settlements in urban areas. They have high death rates among infants, neonates, children less than 5 years old, and mothers. ${ }^{2}{ }^{3}$ Many births initially occurred without health worker support on the floor of filthy makeshift tents. The Government of Pakistan and aid agencies, led by the United Nations High Commission for Refugees, developed a well organised and effective system of primary health care. Specialist care remained dependent on distant government hospitals.

Assessment was undertaken with the help of interviews, group discussions, and questionnaires of families and health workers in one camp (New Jalozai). This revealed that most patients referred to hospital did not avail themselves of this care for the following reasons. The $60-80 \mathrm{~km}$ drive from the camps to hospitals in the nearest city, Peshawar, was tiring and difficult, taking about 1.5 hours. Payment for both the transport and any investigation or treatment at the hospital was beyond the means of most families; indirectly there was loss of several days' earnings. Women could not travel alone, requiring the company of a male relative. Many refugees did not realise the importance of medical care, never having had access to it before. The available government hospitals were grossly overburdened, with extremely limited resources, and most families who did make the effort were poorly satisfied with the care provided.

The Pakistan government and United Nations worked with Child Advocacy International to provide specialist (hospital based) maternal and child health care in two refugee camps (New Shamshatu and Shalman) initially containing around 150000 people, largely women and children. Essential drug and medical supplies were supplemented to include oxygen, intravenous fluids, parenteral antibiotics, bronchodilators, and drugs for gynaecological and obstetric emer-

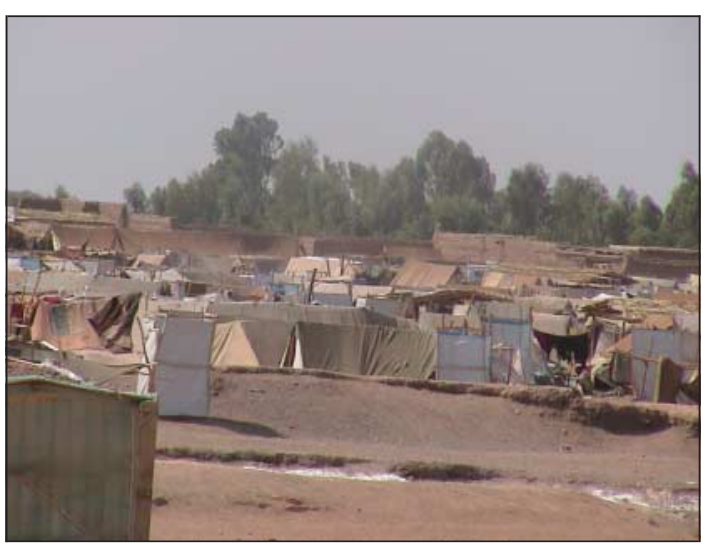

Afghan refugee camp (New Jalozai) in Pakistan 


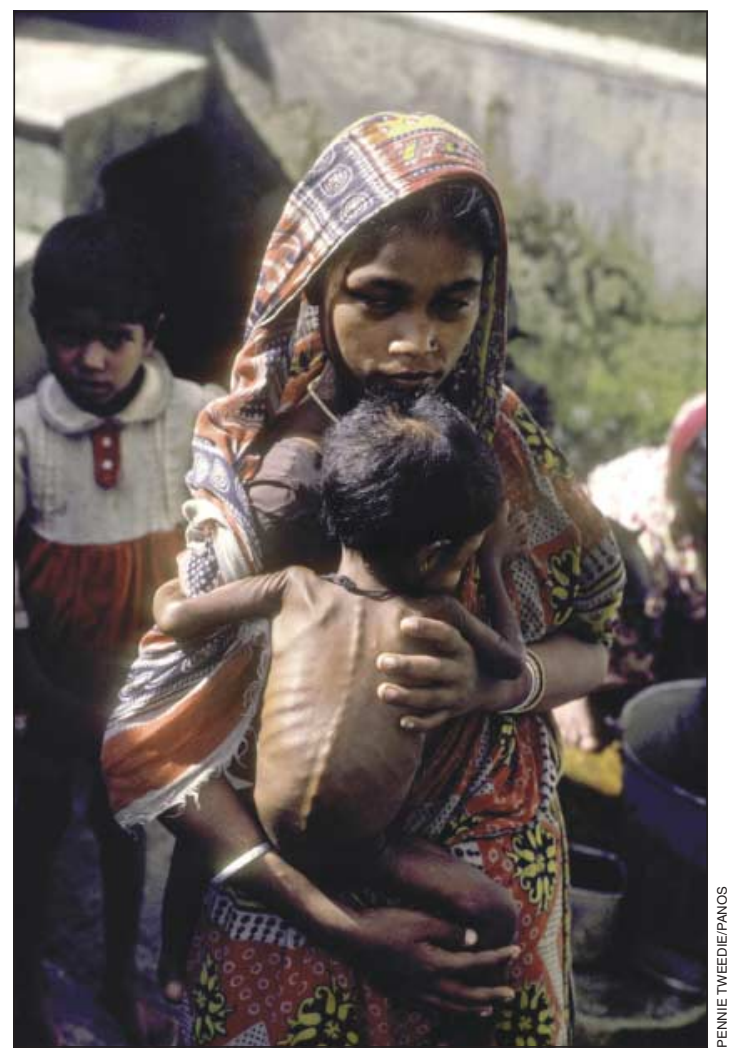

Malnutrition is a major concern in refugee camps

gencies. A labour room with ultrasound scanner and a minor operations theatre were established. Operations were undertaken using ketamine and midazolam for anaesthesia. Inpatient beds were established for women, children, and neonates (including locally made, low cost equipment such as a resuscitaire, heated cots, and a phototherapy unit). Clean toilets and hand washing facilities were provided, as was a 24 hour electricity supply. There was an ambulance to evacuate individuals with serious or rare conditions to teaching hospitals in Peshawar. The presence of a trained paediatrician and obstetrician working in the two camps provided front line staff with opportunities to acquire further skills.

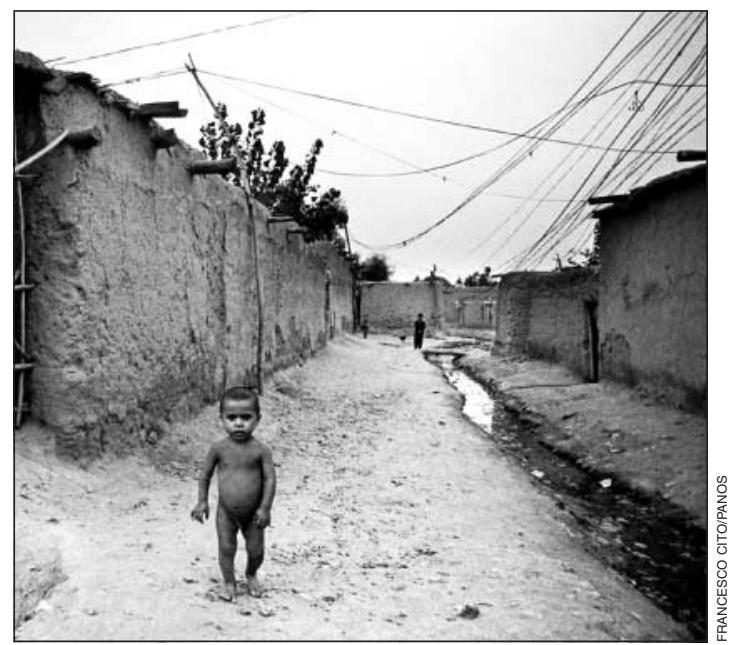

Katcha Garhi refugee camp, Peshawar
A referral system was developed to streamline the flow of patients from all eight basic health units to the hospital services within each camp. From October 2001 to January 2004, 23467 patients (12 850 babies and children and 10617 mothers) were treated. Diseases included severe respiratory problems (45\%) such as pneumonia, asthma, and tuberculosis; severe gastrointestinal infections (35\%) with dehydration; chronic diarrhoea; and serious illnesses such as neonatal sepsis and meningitis. In mothers there was a bank of chronically neglected gynaecological diseases, many originating from previous and unsupported births. Obstetric care-including deliveries $(47 \%$ of patients), contraceptive advice or procedures ( $8 \%)$, and gynaecological procedures (30\%)-was undertaken daily.

The additional cost (over and above the primary care expenses) for this hospital based service was estimated as $\$ 0.15 /$ person/day (for women and children only).

About 8\% of those receiving primary care attended for specialist treatment, with only two or three patients each day requiring referral to the teaching hospitals in Peshawar. This is a lower referral rate for hospital care than has been reported from other countries $(10-20 \%){ }^{4-6}$

Chronic diseases had been largely neglected, probably because they lacked urgency. Yet they caused suffering, not only for the individual, but also for the whole family (particularly if a mother had, for example, depression or a vesicovaginal fistula). ${ }^{7}$ We have already reported a high prevalence of severe mental illness in mothers caring for children in these camps. ${ }^{8}$ There is good evidence that maternal health has a substantial effect on the wellbeing of children. ${ }^{9}{ }^{10}$ The importance of linking maternal and child health care was borne out.

\section{Case study 2: Emergency maternal and child health care in two districts of Pakistan}

Each of the two districts, Nowshera and Gujranwala, has one main government hospital serving local populations of approximately one million and 3.5 million people respectively. A network of primary care facilities existed but without effective linkage with hospitals, where maternal and child health care was available. Outside morning hours, obstetric and paediatric services were provided only by poorly trained generalist nurses and doctors.

The vast majority of pregnant mothers had so little confidence in the care they would receive at these local hospitals that they preferred to deliver their baby at home, usually with support from untrained or poorly trained health workers. Those who developed life threatening complications around delivery were usually not referred or evacuated in time to the hospital.

In the two hospitals we assessed, about $75 \%$ of the essential emergency equipment, drugs, and medical supplies were not present, and staff adequately trained in emergency maternal and child health care were available for only a small part of each day. The transport system between communities and the 


\section{Summary points}

Health care for mothers and children is seriously unsatisfactory in most refugee situations and in the government hospitals of many poorly resourced countries

It is essential to link maternal and child healthcare services in all settings

Integration of primary (home based) health care with adequately functioning hospital based care is important for the success of any healthcare system

Effective ways of safely transferring patients between community care settings and hospital facilities must be in place

hospitals serving them was poor. Many ambulances were broken, funds to pay the drivers or for fuel were limited or absent, and ambulance staff were not trained in basic life support. As a result, the small proportion of the population who could afford it attended private hospitals. The rest remained at home, suffered, and often died.

If deaths and long term or permanent disability are to be avoided, emergency obstetric, neonatal, and paediatric services must be strengthened. The links between home based and hospital services must also be improved by better communication and more coordinated transport systems.

Child Advocacy International and the Advanced Life Support Group, in partnership with WHO Pakistan and the government of Pakistan, are piloting a project termed Emergency Maternal and Child Health (EMCH) in these two districts. It aims to enhance the effectiveness of care in the first few hours after presentation of an emergency by an educational approach that uses skill stations, drills, workshops, and scenarios to train doctors, nurses, and paramedics, with particular emphasis on frontline health workers, predominantly nurses. The project also ensures that, before training starts, sufficient emergency drugs and medical supplies as well as basic low cost but appropriate essential emergency equipment are in place. Local governments in the two districts have agreed to supply all of the missing emergency drugs and medical supplies. Missing equipment is largely being donated.

\section{Conclusions}

The integration of hospital and home based health care in emergency situations such as refugee camps and at the district level of poorly resourced countries can be achieved at relatively low cost. Much effort has been put into enhancing primary (home based) care, as this is cost effective. However, we argue that there has been a relative neglect of hospital based care by both governments and the international community, and the integration of the two requires urgent evaluation and implementation. Local public sector hospitals need to be configured to serve a community and not just to provide episodic care for the few patients who transiently pass through their doors.

Contributors: All the authors were involved in planning, conducting, and implementing the work. AH produced the first draft, and DS produced the final version, which was shared with all the authors. Dr Ghulam Hazrat and Ms Basroon were associated with the project, as paediatrician and nurse respectively. DS and $\mathrm{AH}$ are guarantors for the paper.

Funding: Jemima Khan Afghan Refugee Appeal and John Bush of Lions Clubs International. Several smaller donors also contributed.

Competing interests: $\mathrm{AH}$ and DS have been reimbursed for talking on this subject at international symposiums.

1 Sogan D, Bridel J, Arzomund M, Shepherd C, Southall D. 21st century health care for children in Afghanistan. Pediatrics 1998;102:1193-8.

2 Boss LP, Brink EW, Dondero TJ. Infant mortality and childhood nutritional status among Afghan refugees in Pakistan. Int J Epidemiol 1987;16:556-60.

3 Bartlett LA, Jamieson DJ, Kahn T, Sultana M, Wilson HG, Duerr A. Maternal mortality among Afghan refugees in Pakistan. 1999-2000. Lancet 2002;359:643-9.

4 Starfield B, Forrest CB, Nutting PA, von Schrader S. Variability in physician referral decisions. J Am Board Fam Pract 2002;15:473-80.

5 Forrest CB, Nutting PA, Starfield B, von Schrader S. Family physicians' referral decisions: results from the ASPN referral study. J Fam Pract 2002;51:215-22.

6 Duke T, Tamburlini G. The Paediatric Quality Care Group. Improving the quality of paediatric care in peripheral hospitals in developing countries Arch Dis Child 2003;88:563-5.

7 Benatar SR. Social suffering relevance: for doctors. BMJ 1997;315:1634-5.

8 Rehman A, Hafeez A. Suicidal feelings run high among mothers in refugee camps: a cross sectional survey. Acta Psychiatr Scand 2003;108:392-3.

9 Pattinson RC, Makin JD, Shaw A, Delport SD. The value of incorporating avoidable factors into perinatal audits. S Afr Med J 1995;85:145-7.

10 Salinas AM, Coria I, Reyes H, Zambrana M. Effect of quality of care on preventable perinatal mortality. Int J Qual Health Care 1997;9:93-9.

(Accepted 11 March 2004)

\section{Interactive case report}

\section{A 66 year old with breathlessness}

This case was described on 20 and 27 March (BMJ $2003 ; 698)$. Debate on her management continues on bmj.com (http://bmj.com/cgi/eletters/328/7441/ 698). On 17 April we will publish the outcome of the case together with commentaries on the issues raised by the management and online discussion from the patient, a general practitioner, and relevant experts. 